J. Lake Sci.(湖泊科学), 2009, 21(4): 547-555

http://www.jlakes.org. E-mail: jlakes@niglas.ac.cn

(C2009 by Journal of Lake Sciences

\title{
湖北清江流域胡家溪大型底栖动物群落结构及水质评价 ${ }^{*}$
}

\author{
江 晶, 温芳妮, 顾 鹏, 间云君 ${ }^{* *}$ \\ (华中科技大学生命科学与技术学院, 武汉 430074)
}

摘 要: 2006 年 4 月至 2007 年 3 月, 对清江流域上游一二级支流——胡家溪的大型底栖动物群落结构进行了调查研究, 并利 用生物指数对河水水质进行了系统评价. 结果表明, 共采集到大型底栖动物 87 种, 其中环节动物 3 种, 软甲动物 3 种, 水生昆 虫 76 种, 软体动物 5 种. 群落表现出明显的时空特点, 6 月份的物种最多, 12 月份的物种最少, S5 的物种最多, S1 的物种最少; 各微生境中共有种占据优势, 物种相似性均大于 $75 \%$; 功能摄食群则以收集者占优, 共计达 51 种. 群落密度在 4 月份达到最 大, 为 $3293 \mathrm{ind} . / \mathrm{m}^{2}$; 而生物量则在 12 月份达到最大, 为 $163 \mathrm{~g} / \mathrm{m}^{2}$. 采用 Shannon 多样性指数、生物指数和科级水平生物指数 对胡家溪水质评价的结果是河水水质比较清洁.

关键词: 大型底栖动物; 群落结构; 水质评价; 胡家溪

\section{Community structure of macrozoobentos and bioassessment of water quality in Hujiaxi Stream of Qingjiang River Basin, Hubei Province}

\author{
JIANG Jing, WEN Fangni, GU Peng \& YAN Yunjun \\ (College of Life Science and Technology, Huazhong University of Science and Technology, Wuhan 430074, P.R.China)
}

\begin{abstract}
Community structure of macrozoobenthos and the bioassessment on water quality in a second order river-Hujiaxi Stream of Qingjiang River basin were investigated from April 2006 to March 2007. The results showed that, among collected altogether 87 species of macroinvertebrates, there were 3 species of Annelida, 3 species of Mollusca, 76 species of aquatic insects, and 5 species of Malacostraca. The community structure exhibited obvious spatial and temporal variations. The species number reached its peak in June, and descended to the lowest in December. There was the largest species number in Site 5, and more species macroinvertebrates were presented in June than those in other months. Over $75 \%$ of the collected species could inhabit in all six types of microhabitats. The density of the community reached its peak in April at $3293 \mathrm{each} / \mathrm{m}^{2}$, while biomass attained its peak in December at $163 \mathrm{~g} / \mathrm{m}^{2}$. The water quality was bio-assessed with Shannon-Weaner diversity, Biotic Index $(B I)$ and Family Biotic Index (FBI), and results showed that the river water was fairly clean during the sampling period. Considering the coincidence with physical-chemical parameters, $B I$ and $F B I$ bio-assessment methods were much fit to apply in rivers of China.
\end{abstract}

Keywords: Macrozoobenthos; community structure; biomonitoring; water quality; Hujiaxi Stream

底栖动物具有生命周期较长, 行动缓慢, 分布广泛, 形体较易辨认等特点, 在水生态系统的物质循 环和能量流动中发挥着不可替代的作用, 不同种类底栖动物对环境条件的适应性及对污染等不利因素的 耐受力和敏感程度不同, 因此底栖动物的种群结构、优势种类、现存量等参数可以反应环境因素的长期 变化情况，已越来越广泛地被人们用于环境生物监测和生态评价 ${ }^{[1]}$. 我国应用底栖动物群落结构对河流 水质进行的生态学评价主要集中在黄河、淮河、珠江以及长江中下游流域, 涉及长江上游及上游支流的 研究则相对满 $\Sigma^{[2-6]}$. 作者于 2006 年 4 月至 2007 年 3 月间对清江流域一二级河流——胡家溪的大型底栖

* 国家自然科学基金(30640024)项目资助. 2008-09-01 收稿; 2008-10-20 收修改稿. 江晶, 女，1984 年生，硕士研究生; E-mail: jingjingiaiv@163.com.

** 通讯作者; E-mail: yanyunjun@tom.com. 
动物群落结构进行了为期一年的系统研究, 以期增进对长江上游河流, 特别是三峡水库成库后长江上游 河流生物群落及水质变化情况的了解. 胡家溪是长江支流清江的一条二级河流, 位于湖北省长阳土家族 自治县境内 $\left(111^{\circ} 03^{\prime}-111^{\circ} 35^{\prime} \mathrm{E}, 30^{\circ} 27^{\prime}-30^{\circ} 28^{\prime} \mathrm{N}\right)$, 流域面积约 $50 \mathrm{~km}^{2}$. 胡家溪两侧为山脉, 植被覆盖率较高, 河两岸着生灌木和杂草. 流域地区为典型亚热带气候, 雨季一般自 4 月开始, 9 月底或 10 月初结束. 河两 岸尚未建设工业设施, 为农田和居舍. 全年水温变化范围在 $10-28^{\circ} \mathrm{C}$ 之间.

\section{1 工作方法}

\section{1 采集点和采样时间}

根据河流生境类型(底质、水流速度、水生植物分布等)从上游至下游选择了 6 个采样点(图1). 1站(S1) 河两岸生长茂密的灌木和杂草, 河面较窄, 约 $2 \mathrm{~m}$ 宽, 部分被遮蔽, 水流较缓, 底质为粗沙; 2站(S2)位于一 支流汇人口, 河面较窄约 $2 \mathrm{~m}$ 宽, 水流较缓, 河中以细沙为主; 3 站(S3)在一小瀑布下方, 水流较急, 河底以 布满苔藓的巨石为主; 4站(S4)位于一堰塘下游浅水区, 地势平缓, 水流缓慢, 底质为石灰岩, 河边杂草较 少; 5站(S5)河面变宽, 河面约 $3 \mathrm{~m}$ 宽, 河底以卵石为主, 腐殖质较多, 水流较急; 6站(S6)位于一排污口的下 游, 河面约 $4 \mathrm{~m}$ 宽, 水流较急, 河底碎石较多. 其河水的理化性质见表 1 (年均值).

样品采集时间一般为每月的 5 日左右，每月一次，为期一年，即 2006 年 4 月至 2007 年 3 月.

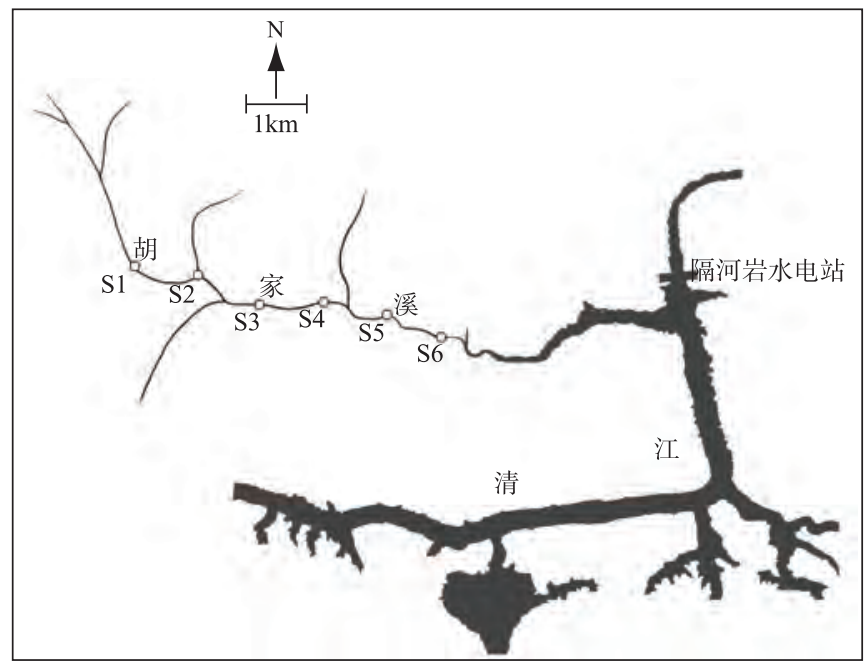

图 1 胡家溪及采样点分布

Fig.1 Distribution of sampling sites at Hujiaxi Stream

表 1 胡家溪的理化性质(年平均值)

Tab.1 Main physical and chemical characteristics of Hujiaxi Stream

\begin{tabular}{cccccccccc}
\hline $\mathrm{pH}$ & $\begin{array}{c}\text { 悬浮物 } \\
(\mathrm{mg} / \mathrm{L})\end{array}$ & $\begin{array}{c}\text { 总磷 } \\
(\mathrm{mg} / \mathrm{L})\end{array}$ & $\begin{array}{c}\text { 总氮 } \\
(\mathrm{mg} / \mathrm{L})\end{array}$ & $\begin{array}{c}\text { 氨氮 } \\
(\mathrm{mg} / \mathrm{L})\end{array}$ & $\begin{array}{c}\text { 亚硝酸盐氮 } \\
(\mathrm{mg} / \mathrm{L})\end{array}$ & $\begin{array}{c}\text { 硝酸盐氮 } \\
(\mathrm{mg} / \mathrm{L})\end{array}$ & $\begin{array}{c}\text { 溶解氧 } \\
(\mathrm{mg} / \mathrm{L})\end{array}$ & $\begin{array}{c}\text { 高锰酸盐 } \\
\text { 指数 }\end{array}$ & $\begin{array}{c}\mathrm{BOD}_{5} \\
(\mathrm{mg} / \mathrm{L})\end{array}$ \\
\hline 7.4 & 5.3 & 0.064 & 1.362 & 0.89 & 0.175 & 0.45 & 6.28 & 4.2 & 3.3 \\
\hline
\end{tabular}

\section{2 标本采集及处理}

定量采集使用 60 目的 D 型网或 60 目的 Surber 网, 每样点 1 次, 3 个重复. 样品经 60 目铜篮篮洗后, 剩 余物带回实验室, 置于白磁盘活体挑选, 标本以 $10 \%$ 福尔马林固定保存. 标本经鉴定、计数和称重后, 换 算成每平方米的含量. 底栖动物鉴定工作参考相关文献 ${ }^{[7-10]}$. 


\section{3 水质的生物学评价}

根据胡家溪大型底栖动物群落的特点及取样数据, 选择以下生物指数进行水质评价.

1.3.1 物种多样性指数 (Shannon-Wiener)指数:

$$
H^{\prime}=-\sum_{n}^{s} P_{i} \ln P_{i}
$$

式中: $S$ 为总物种数; $P_{i}$ 为第 $i$ 种的个体数占总个体数的比例; $n_{i}$ 为第 $i$ 种的个体数; $N$ 为所有种的个体总数. 评价标准: 指数值 $>3$, 清洁; 2-3 轻污染; 1-2 中污染; 0-1 重污染.

1.3.2 科级水平生物指数 $(F B I)^{[11]}$ :

$$
F B I=\sum_{i=1}^{F} n_{i} t_{i} / N
$$

式中: $n_{i}$ 为第 $i$ 科的个体数; $t_{i}$ 为第 $i$ 科的耐污值; $N$ 为各科个体总和; $F$ 为科数. 水质评价标准: $F B I=0.00-3.75$ 极清洁； 3.76-4.25很清洁；4.26-5.00清洁； 5.01-5.75一般；5.76-6.50轻度污染； 6.51-7.25污染； 7.26-10.00 严重污染.

1.3.3 生物指数 $(B I)^{[12]}$ :

$$
B I=\sum_{i=1}^{S} n_{i} a_{i} / N
$$

式中: $n_{i}$ 为第 $i$ 分类单元(属或种)的个体数; $a_{i}$ 为第 $i$ 分类单元(属或种)的耐污值; $N$ 为各分类单元(属或种)的 个体总和; $S$ 为种类数. 水质评价标准: $B I=0.00-3.50$ 极清洁; 3.51-4.50很清洁; 4.51-5.5清洁; 5.51-6.50一 般; 6.51-7.50轻度污染; 7.51-8.50污染; 8.51-10.00严重污染.

1.3.4 Margalef丰富度指数指数：

$$
D=(S-1) / \ln N
$$

1.3.5 Simpson指数:

$$
D=1-/\left[\sum_{i=1}^{S}\left(n_{i} / N\right)^{2}\right]
$$

式中: $S$ 为总物种数; $P$ 为第 $i$ 种的个体数占总个体数的比例; $n_{i}$ 为第 $i$ 种的个体数; $N$ 为所有种的个体总数.

1.4 不同微生境群落结构的比较

采用S $\phi$ rensen指数 $S=2 c /(a+b)^{[13]}$ 比较不同微生境的物种相似性.

\section{5 数据分析}

上述参数及其它数据分析均应用Excel 5.0 软件进行处理和分析.

\section{2 结果}

\section{1 大型底栖动物群落构成及动态}

在胡家溪共采集到大型底栖动物 87 种，其中环节动物 3 种，占 $3.45 \%$, 软体动物 5 种，占 $5.75 \%$, 水 生昆虫 76 种, 占 $87.35 \%$, 软甲动物 3 种, 占 $3.45 \%$.

2.1 .1 群落结构的时间动态 2006 年 6 月份的物种最多, 为 54 种, 8 月其次, 为 49 种(图 2a), 这可能由于 温度升高越冬一代的底栖动物出现, 并在暮春产卵, 个体迅速长大，在夏季数量较多，到夏末(8 月)和秋 季又开始大量繁殖. 12 月的物种最少, 仅为 34 种, 11 月的物种数也仅有 35 种, 这可能与冬季水温较低, 食 物资源有限，稀有种出现较少有关.

2.1.2 群落结构的空间动态 S5 的物种最多, 达 65 种, S3 次之, 为 64 种(图 2b), 这可能由于 S5 的底质为 卵石, S3 的底质为布满了苔藓的巨石，两者底质均较为稳定，尤其适合滤食者的生存，且 S5 的水草较多， 为底栖动物创造了生活、摄食、繁殖的环境，同时为它们避免被鱼类等捕食提供了良好的躲避场所. S1 的物种最少, 仅为 50 种, 可能与其底质是粗沙有关, 粗沙底质不稳定, 不适合底栖动物的生长, 如摇蚊 的密度在沙质中通常较小

\section{2 胡家溪底栖动物群落的功能摄食类群}

87 种大型底栖动物中，共有撕食者 7 种，占 $8.05 \%$; 收集者 51 种，占 $58.6 \%$; 刮食者 7 种，占 $8.05 \%$; 

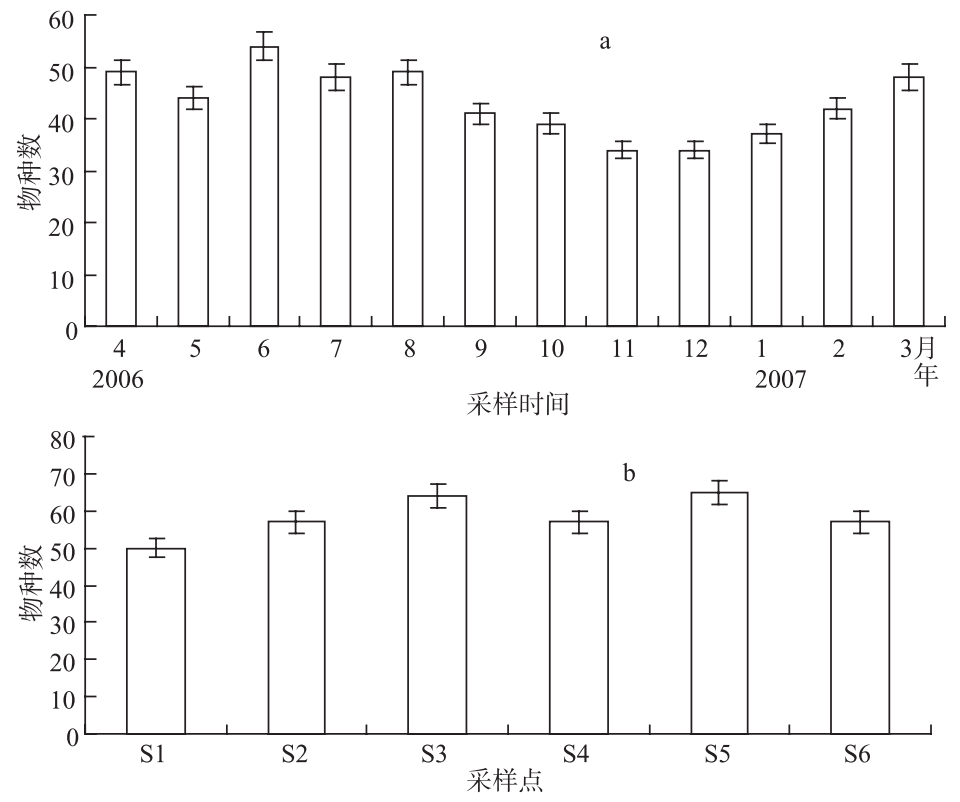

图 2 胡家溪底栖动物物种数的时间(a)和空间(b)动态

Fig.2 Temporal(a) and spatial(b) dynamics of the macrozoobenthos species number in Hujiaxi Stream

捕食者 22 种，占 $25.3 \%$ (表 3). 功能摄食群分布较为合理. S1 的撕食者比其他样点多, 这是由于 S1 位于 上游河段中落叶、树枝或其他有机物质残渣依赖于撕食者的分解. S2、S3 以滤食较细颗粒有机质为生 的收集者较多, 而随着粗颗粒有机物质经过撕食者、收集者和微生物等的共同利用后逐渐分解变细, 同时上游水生生物也被带到下游，因此 S4、S5、S6 的捕食者明显增加，上述结果与 “河流连续统概念” 基本一致 ${ }^{[13]}$.

表 3 各微生境大型底栖动物的功能摄食类群

Tab.3 Functional feeding groups of macrozoobenthos in different microhabitats in Hujiaxi Stream

\begin{tabular}{ccccccc}
\hline 功能摄食 & \multicolumn{7}{c}{ 采样点 } \\
\cline { 2 - 7 } 类群 & $\mathrm{S} 1$ & $\mathrm{~S} 2$ & $\mathrm{~S} 3$ & $\mathrm{~S} 4$ & $\mathrm{~S} 5$ & $\mathrm{~S} 6$ \\
\hline 撕食者 & 7 & 4 & 5 & 4 & 4 & 3 \\
收集者 & 25 & 34 & 38 & 31 & 35 & 35 \\
刮食者 & 4 & 4 & 5 & 5 & 7 & 2 \\
捕食者 & 14 & 15 & 16 & 17 & 19 & 17 \\
总计 & 50 & 57 & 64 & 57 & 65 & 57 \\
\hline
\end{tabular}

\section{3 胡家溪各微生境底栖动物群落的生物多样性}

根据胡家溪大型底栖动物群落的特点及取样数据, 选择 Margalef 丰富度指数、Shannon-Wiener 指数、 Simpson 多样性指数进行数据及结果分析. 各微生境(采样点)的生物多样性指数时间动态(图 3)可看出, 与 其它两种多样性指数相比, Simpson 多样性指数变动幅度最大, 而且并不是任何时候与其它两种指数的变 化趋势相吻合. 总体上, S5 的 Simpson 指数变动最平稳(变化范围是 4.26-7.52), 可能因为 S5 底质为卵石, 较为稳定, 故生境的变动幅度也较小. $\mathrm{S} 1$ 的 Simpson 指数变动最大(变化范围是 2.57-11.05), 可能与 $\mathrm{S} 1$ 的 底质为粗沙，容易受到冲刷，生境的变动幅度较大有关. 

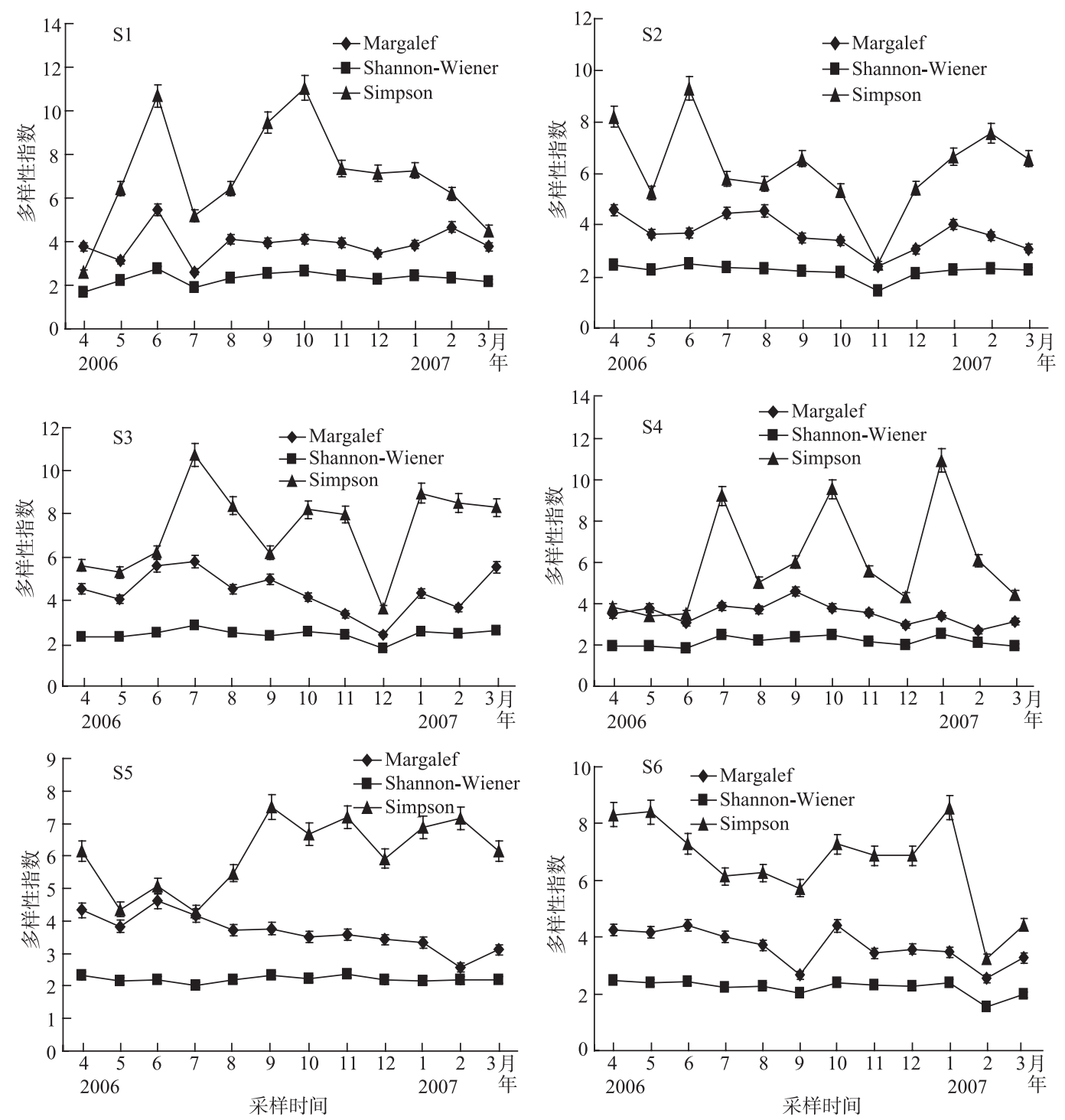

图 3 胡家溪各采样点底栖动物群落结构生物多样性指数的时间动态

Fig.3 Temporal variations of biodiversity of the macrozoobenthos community in different sampling stations in Hujiaxi Stream

\section{4 胡家溪不同微生境底栖动物群落结构的比较}

计算出各微生境的 S $\phi$ rensen 相似指数见表 4. 总体上, 生活在各微生境中的共有种占据优势，最小的 相似性也达到 0.75. S4 和 S5、S3 和 S6、S4 和 S6 的相似性更高达 $0.85,0.84,0.82$. 较高的群落相似性一 方面多数物种能够适应河流的多种微环境, 以保证旱季河流物种多样性的延续; 另一方面可能由于胡家 溪的水质较清洁, 食物充足, 底栖动物群落结构趋于完整.

\section{5 优势物种的现存量动态}

根据胡家溪各种底栖动物的出现频次及其现存量(周年均值)在全部底栖动物和本类群底栖动物中所 占的比例，确定胡家溪的优势种为以下 10 种：蜉蝣目扁蜉科的 Electrogena $\mathrm{sp}$ 、、细蜉科的 Caenis sp.、小 裳蜉科的 Choroterpes sp.、四节蜉科的 Indobaetis sp.; 毛翅目纹石蛾科的 Hydropsyche sp.1、多距石蛾科 
表 4 胡家溪各种微生境的物种相似性

Tab.4 Similarity of species composition between microhabitats in Hujiaxi Stream

\begin{tabular}{ccccccc}
\hline 采样点 & $\mathrm{S} 1$ & $\mathrm{~S} 2$ & $\mathrm{~S} 3$ & $\mathrm{~S} 4$ & $\mathrm{~S} 5$ & $\mathrm{~S} 6$ \\
\hline S1 & 1 & - & - & - & - & - \\
S2 & 0.79 & 1 & - & - & - & - \\
S3 & 0.81 & 0.79 & 1 & - & - & - \\
S4 & 0.80 & 0.81 & 0.79 & 1 & - & - \\
S5 & 0.80 & 0.79 & 0.78 & 0.85 & 1 & - \\
S6 & 0.79 & 0.81 & 0.84 & 0.82 & 0.75 & 1 \\
\hline
\end{tabular}

的低头石虫 Neureclipsis sp.; 双翅目摇蚊科的 Conchapelopia sp.、波特真开氏摇蚊 E. potthasti，以及十足 目的圆顶华溪蟹 S. teritism、中华新米虾 C. denticulata.

10 种优势物种的现存量动态如图 4 所示. 除 2 种石虫外, 其余 8 种优势物种的密度和生物量在 9 月 均较低, 这可能与 9 月胡家溪的雨水较多, 生物个体和食物较多地被冲走有关. 而 2 种石寔均属于过滤收 集者，且有附着器官，在流速较高的微生境中不会被冲走，而且更利于其有效滤食.

对 10 种优势种的现存量进行统计分析表明, 4 种蜉蝣目优势种的密度随时间均差异极显著 $(P=0.0005)$, 同一月份 4 种蜉蝣间的差异不显著 $(P=0.1306)$, 生物量随时间均差异极显著 $(P=0.0003)$, 同一月份 4 种蜉 蝣间的差异显著 $(P=0.0272) .2$ 种摇蚊优势种的密度随时间均差异极显著 $(P=0.0011)$, 同一月份 2 种摇蚊间 的差异不显著 $(P=0.3837)$, 生物量随时间均差异极显著 $(P<0.0001)$, 同一月份 2 种摇蚊间的差异不显著 $(P=0.2077) .2$ 种毛翅目优势种的密度随时间均差异极显著 $(P=0.0004)$, 同一月份 2 种毛翅目间的差异不显 著 $(P=0.306)$, 生物量随时间均差异极显著 $(P=0.0006)$, 同一月份 2 种毛翅目间的差异显著 $(P=0.5507)$.

\section{6 群落的现存量周年动态}

胡家溪各样点的现存量周年平均值(表 5)可以看出, S5 的密度和生物量在整个群落中所占的比例均最大. 这可能与 S5 的物种数最多有关, S5 的底质为卵石, 底质较稳定, 且 S5 的水草较多, 生境异质性高. S6 的密度 在整个群落中所占的比例较大, 但其生物量在整个群落中所占的比例却最小, 这可能与个体较大的物种较少 (S6 位于河口, 鱼类相对较多, 对个体大的底栖动物造成较大摄食压力), 而生物量较小的摇蚊分布在 S6 相对 较多有关. S3 的苔藓通过光合作用, 为水体提供丰富的氧气，好氧性动物大量出现，且密度和生物量也较高. S4 的密度和生物量均较小, 可能与其石灰岩底质有关, 石灰岩底质不可能维持较多的水生植物生长, 生境较 单一. 对各样点的现存量进行统计分析表明, 6 个样点随时间密度差异均极显著 $(P<0.0001)$, 同一月份不同采 样点间的密度差异也极显著 $(P<0.0001) .6$ 个样点随时间生物量差异不显著 $(P=0.700)$, 而同一月份不同采样点 间的生物量差异极显著 $(P=0.003)$.

表 5 胡家溪各样点的现存量周年均值和比例

Tab.5 Annual mean standing stock of various sampling stations in Hujiaxi Stream

\begin{tabular}{ccccc}
\hline 采样点 & 密度年均值 $\left(\mathrm{ind} . / \mathrm{m}^{2}\right)$ & 密度所占比例 $(\%)$ & 生物量年均值 $\left(\mathrm{g} / \mathrm{m}^{2}\right)$ & 生物量所占比例 $(\%)$ \\
\hline S1 & 136.08 & 11.51 & 4.3732 & 19.41 \\
S2 & 130.67 & 11.05 & 3.8726 & 17.18 \\
S3 & 210.58 & 17.81 & 4.0773 & 18.01 \\
S4 & 168.58 & 14.26 & 3.2474 & 14.41 \\
S5 & 278.58 & 23.56 & 6.0965 & 27.05 \\
S6 & 258.08 & 21.82 & 0.8680 & 3.85 \\
\hline
\end{tabular}

由群落的现存量周年动态(图 5)可知, 群落密度最大值出现在 4 月, 为 $3811 \mathrm{ind} . / \mathrm{m}^{2}$ 、随后下降, 直至 

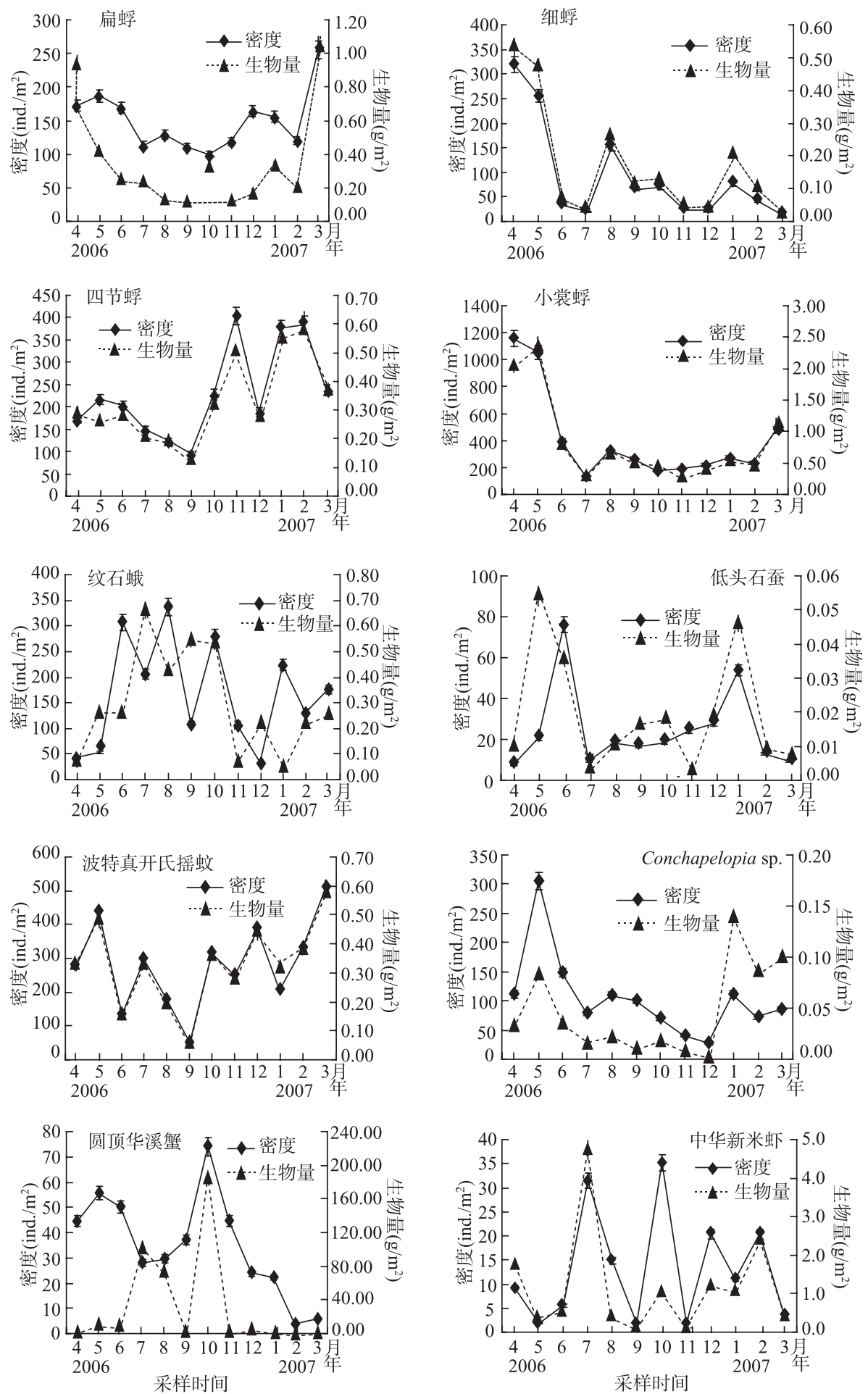

图 4 胡家溪主要优势种的现存量周年动态

Fig.4 Annual variations of standing stocks of dominant species in Hujiaxi Stream 


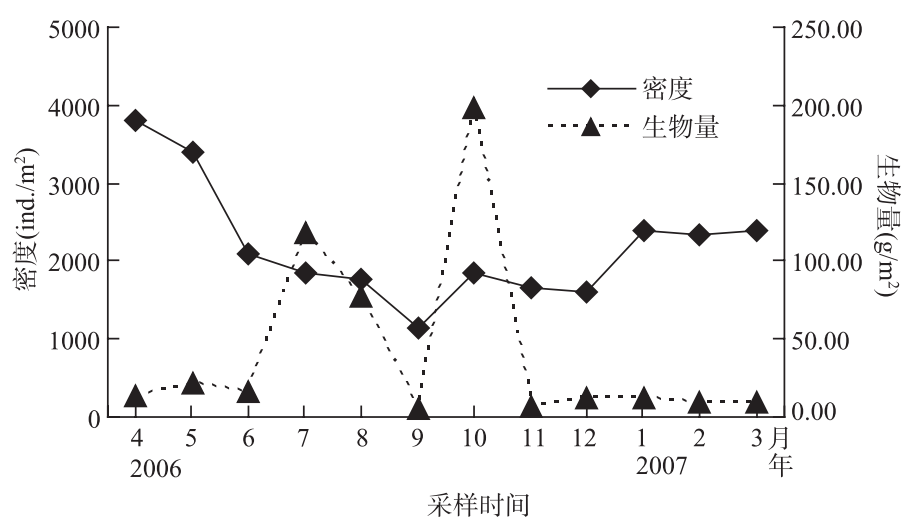

图 5 胡家溪的底栖动物群落现存量周年动态

Fig.5 Annual variation of standing stock of zoobenthos community in Hujiaxi Stream

9 月跌至谷底, 为 $1141 \mathrm{ind} . / \mathrm{m}^{2}$; 生物量的变化呈现双峰型, 第一个峰值出现在 7 月, 为 $117.82 \mathrm{~g} / \mathrm{m}^{2}$ 、第二 个峰值出现在 10 月, 为 $197.77 \mathrm{~g} / \mathrm{m}^{2}$, 生物量的其余各月维持在较低水平. 群落的密度和生物量的变化趋 势不同步，可能与较大个体的物种，如圆顶华溪蟹、中华新米虾的生物量在 7 月、10 月较大有关. 且当 圆顶华溪蟹、中华新米虾的密度较大时, 会对其它生物(如摇蚊)构成较大压力, 使得其它生物的密度和生 物量相应减少. 群落的密度和生物量的周年平均值分别为 $2190 \mathrm{ind} . / \mathrm{m}^{2}, 41.77 \mathrm{~g} / \mathrm{m}^{2}$. 群落的密度和生物量 的周年均值均比同地区的叹气沟河小, 可能与叹气沟河的郁闭性更高, 外源性食物更丰富有关 ${ }^{[6]}$

\section{7 胡家溪的水质评价}

$F B I$ 生物指数和 $B I$ 生物指数的水质评价结果基本吻合, 在 $\mathrm{S} 2$ 和 $\mathrm{S} 4$ 的洁净度排序上略有区别(表 6). S1-S5 的水质均属于清洁, S6 用 FBI 生物指数、BI 生物指数评价属于一般, 而用 Shannon 生物指数评价 属于清洁. 总体上, 无论采用哪种生物指数, 上游 S2、S4、S5 采样点的水质优于下游 S6. 在采集到的标 本中, 有一些对水质特别敏感的类群, 如扁蜉、小裳蜉、纹石蛾等在 S4、S5 的密度较大, 而在 S6 位于一 排污口的下游, 耐污能力相对较强的类群比其它样点多, 如摇蚊科的 Paratanytarsus sp.、Glyptotendipes sp., 其耐污值在 7.0 以上.

表 6 各采样点的生物指数和水质评价

Tab.6 Biotic Indexes and bioassement of water quality of different stations

\begin{tabular}{|c|c|c|c|c|c|c|c|c|c|}
\hline \multirow[b]{2}{*}{ 采样点 } & \multicolumn{3}{|c|}{$B I$ 生物指数 } & \multicolumn{3}{|c|}{$F B I$ 生物指数 } & \multicolumn{3}{|c|}{ Shannon 生物指数 } \\
\hline & 指数值 & $\begin{array}{l}\text { 水质 } \\
\text { 级别 }\end{array}$ & $\begin{array}{c}\text { 洁净度 } \\
\text { 排序 }\end{array}$ & 指数值 & $\begin{array}{l}\text { 水质 } \\
\text { 级别 }\end{array}$ & $\begin{array}{c}\text { 洁净度 } \\
\text { 排序 }\end{array}$ & 指数值 & $\begin{array}{l}\text { 水质 } \\
\text { 级别 }\end{array}$ & $\begin{array}{c}\text { 洁净度 } \\
\text { 排序 }\end{array}$ \\
\hline $\mathrm{S} 1$ & 4.96 & 清洁 & 4 & 4.38 & 清洁 & 4 & 3.09 & 清洁 & 5 \\
\hline S2 & 4.67 & 清洁 & 1 & 4.33 & 清洁 & 2 & 3.46 & 清洁 & 2 \\
\hline S3 & 5.06 & 清洁 & 5 & 4.47 & 清洁 & 5 & 3.15 & 清洁 & 3 \\
\hline S4 & 4.72 & 清洁 & 2 & 4.28 & 清洁 & 1 & 3.85 & 清洁 & 1 \\
\hline S5 & 4.74 & 清洁 & 3 & 4.36 & 清洁 & 3 & 3.14 & 清洁 & 4 \\
\hline S6 & 5.78 & 轻污 & 6 & 6.55 & 轻污 & 6 & 3.03 & 清洁 & 6 \\
\hline
\end{tabular}

\section{3 讨论}

在对胡家溪的 6 个不同微生境底栖动物群落结构的比较中发现, 有 $75 \%$ 以上的物种可以适应生存于 河流的各种微生境. $25 \%$ 的物种则在不同定程度上反映出微生境间的差异, 生物多样性的变化与微生境 
的变化密切相关.

比较了各微生境底栖动物的现存量的变化. 结果表明, 密度在卵石、片砾石中较高(S5、S6、S3), 粗

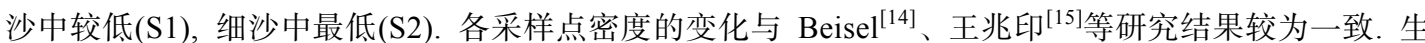
物量在卵石中 $(\mathrm{S} 5)$ 最高, 在粗沙 $(\mathrm{S} 1)$ 、细沙 $(\mathrm{S} 2)$ 、石灰岩 $(\mathrm{S} 4)$ 底质中较少，在碎石中 $(\mathrm{S} 6)$ 最少. 各采样点 生物量的变化与 Beisel ${ }^{[13]}$ 、龚志军 ${ }^{[16]}$ 的结论不一致. 这与胡家溪 S6 的轻微污染有关, 碎石底质一般比 粗沙、细沙更稳定, $\mathrm{S} 6$ 轻微污染导致该处耐轻污物种较多(主要是摇蚊中的一部分)，而摇蚊本身的生物 量较小.

用生物学方法评价胡家溪的水质, 物种多样性指数 Shannon 指数由于以生物分类单元为基础, 适用于 各种水体的水生生物群落, 但由于没有考虑各物种(类群)的耐污值, 当耐污种替代敏感种时对水质的评价 可能比实际值高(S6). 生物指数评价法既考虑了水生生物本身的耐污值, 又考虑了物种的个体数, 增强了 评价的可靠性. 科级水平生物指数评价法, 由于样品只需要鉴定到科级分类单元, 省时省力, 但同一科内, 不同属、种间耐污能力有时差异较大, 因而相对也较粗放; $B I$ 生物指数由于鉴定到了属或种, 比 $F B I$ 生物指 数精确度更高 ${ }^{[17]}$. 在较清洁的水体中 (S1-S5), 同一微生境的 $F B I$ 生物指数比 $B I$ 高, 这与 Hilsenhoff ${ }^{[10]}$ 的 结论相似.

总体看来, 由于污染与非污染因子均影响群落结构和功能, 单一的生物指数很难准确反映某一地区 的水质状况, 因此应选择多种生物指数、并结合种群生态学、理化检测, 综合评定水质. 生物学方法评定 胡家溪的水质为较清洁, 与理化性质判定水质为 II 类较为一致. 下游(S6)的轻微污染主要是沿岸居民的 生活排污和农田施肥等农业面源污染所致。

\section{4 参考文献}

[1] 王备新, 杨莲芳. 我国东部底栖无脊椎动物主要分类单元耐污值. 生态学报, 2004, 24(12): 2769-2775.

[2] 段学花, 王兆印, 程冬升. 典型河床底质组成中底栖动物群落及多样性. 生态学报, 2007, 27(4): 1664-1672.

[3] Epler JH. Identification Manual for the Larval Chironomidae (Diptera) of North and South Carolina, EPA, USA. 2001.

[4] 刘 玉, Vermaat JE, Ruyter ED. 珠江、流溪河大型底栖动物分布和氮磷因子的相关分析. 中山大学学报(自然科学版), 2003, 42(1): 95-99.

[5] 夏爱军, 陈校辉, 蔡永祥. 长江江苏段底栖动物群落结构现状及其水质的初步评价. 海洋渔业, 2006, 28(4): 272-277.

[6] 苏华武, 江 晶, 温芳妮等. 清江流域叹气沟河底栖动物群落结构与水质生物学评价. 湖泊科学, 2008, 20(4): 403-411.

[7] 周长发, 归 鸿, 周开亚. 中国蜉蝣目稚虫科检索表(昆虫纲). 南京师大学报(自然科学版), 2003, 26(2): 65-68.

[8] 大连水产学院主编. 淡水生物学(上册). 北京: 农业出版社, 1978: 291-334.

[9] 梁象秋, 方纪祖, 杨和荃. 水生生物学(形态和分类). 北京: 中国农业出版社, 1995: 200-252.

[10] 田立新, 杨莲芳. 中国经济昆虫志(第49册). 北京: 科学出版社, 1996: 15-21.

[11] Hilsenhoff WL. Rapid field assessment of organic pollution with a family level biotic index. Journal of North American Benthological Society, 1988, 7(1): 65-68.

[12] Hilsenhoff WL. An improved biotic index of organic stream pollution. Great Lakes Entomologist, 1987, 20: 31-39.

[13] 董哲仁. 河流形态多样性与生物群落多样性. 水利学报, 2003, 11: 1-7.

[14] Beisel JN, Usseglio-Polatera P, Thomas S et al. Stream community structure in relation to spatial variation: the influence of mesohabitat characteristics. Hydrobiologia, 1998, 389: 73-88.

[15] 段学花, 王兆印, 田世民. 河床底质对大型底栖动物多样性影响的野外试验. 清华大学学报(自然科学版), 2007, 47(9): $1553-1556$

[16] 龚志军. 杭州西湖和安徽巢湖底栖动物生态学的初步研究. 杭州: 浙江大学, 2004: 58-79.

[17] 童晓立, 胡慧建, 陈思源. 利用水生昆虫评价南昆山溪流的水质. 华南农业大学学报, 1995, 16(3): 6-10 